\title{
Adjustable speed operation of a hydropower plant associated to an irrigation reservoir
}

\author{
Juan I. Perez , Jose R. Wilhelmi, Luis Maroto

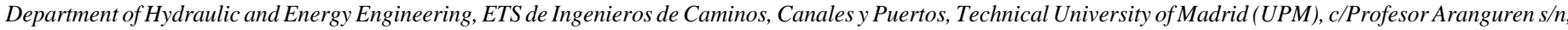 \\ 28040 Madrid, Spain
}

Keywords:

Hydropower generation

Adjustable speed operation

Energy and operational gains

Irrigation reservoir

\begin{abstract}
A B S T R A C T
This paper deals with the issue of adjustable speed operation (ASO) of hydropower plants. The main idea of this technique is to allow the turbine speed to change in accordance with hydraulic conditions, thus improving the overall unit efficiency. General technical aspects of ASO are further discussed with special emphasis on the energy and operational benefits that may potentially result from its application. In order to assess these benefits, annual operation of a hydropower plant associated to an irrigation reservoir has been simulated under different scenarios, with both adjustable and fixed speed. Turbine operating range proved to be wider with ASO. In addition, simulation results confirm that considerable energy gains are expected to be obtained.
\end{abstract}

\section{Introduction}

Interest in sustainable energy systems is continuously increasing nowadays as it is reflected in the 7th EU Framework Program for Research and Technological Development, where one of the main activities of the energy thematic area is focused on energy efficiency and savings. Hydropower is considered to be a competitive and mature technology as well as the most cost effective renewable energy resource. Although it currently provides over $80 \%$ of all renewable energy, there still exists a large technically feasible hydropower potential to be developed, widely spread all over the world

Conventional hydro generating units operate at fixed speed so as to provide energy to the fixed-frequency electric grid. In such cases, head and discharge deviations involve important decreases in efficiency. ASO allows the turbine speed to change in accordance with hydraulic conditions so that the efficiency is maximized. ASO in small hydropower plants has recently been tested in several European projects , thus proving its technical feasibility.

With respect to its economic feasibility, it has been demonstrated that conventional hydro generating units can operate within adjustable speed bands of up to about $\pm 25 \%$ with no increase in turbine cost and only modest increase in generator cost . In addition, there has been a significant drop in prices of electronic frequency converters during the last few years, so the additional investment necessary for such devices is likely to be offset with the performance improvements gained by operating at variable speed.

Besides the inherent energy efficiency improvements, some operational benefits can be obtained by means of ASO. On one hand, ASO allows, in hydro plants with certain regulating capacity, to generate the same amount of energy with a reduced flooded area, thus giving rise to environmental benefits. On the other hand, increased efficiency operation tends to extend equipments life and to reduce long term maintenance requirements.

In this paper, annual simulations,

, have been carried out in a real case study, in order to evaluate adjustable speed operation in different scenarios, given by different weekly flows and different initial reservoir volumes. For this task, a double-purpose reservoir located in the northern area of Spain, where irrigation use is given priority over hydropower generation, has been used.

The paper is organized as follows. In the next section, the basic idea of ASO is presented through adequate figures and analytical formulas. Next, hydro plant data and simulation results are reported and further discussed. Lastly, main conclusions of the study are presented.

\section{General technical aspects}

Reaction hydraulic turbines absorb part of the water kinetic and potential energy in the form of mechanical energy. This energy transfer takes place in the turbine runner blades and is given by the well-known Euler's equation (1). This equation is obtained by applying the law of conservation of angular momentum to the fluid inside the turbine (see Fig. 1) 
$g H_{u}=U i C i \cos a . i-u_{2} c_{2} \cos \mathrm{a}_{2}$

- $\mathrm{g}$ is the gravity acceleration $\left(9.81 \mathrm{~m} / \mathrm{s}^{2}\right)$.

- $\mathrm{H}$, is the effective head (m).

- $U$ ] is the runner peripheral speed at the water inlet $(\mathrm{m} / \mathrm{s})$.

- $u_{2}$ is the runner peripheral speed at the water outlet $(\mathrm{m} / \mathrm{s})$.

- $\mathrm{Ci}$ is the water velocity at the water inlet $(\mathrm{m} / \mathrm{s})$.

- $\mathrm{c}_{2}$ is the water velocity at the water outlet $(\mathrm{m} / \mathrm{s})$.

- oci is the water angle of incidence at the water inlet.

- $\mathrm{a}_{2}$ is the water angle of incidence at the water outlet.

The hydraulic efficiency $r$ relates the mechanical energy absorbed by the turbine, or effective head $\mathrm{H}$," to the available hydraulic energy at the turbine inlet, or net head $\mathrm{H}$,. Usually, the generator efficiency is considered constant over a wide operating range; however, the hydraulic efficiency depends significantly on both the water discharge $q$ and the net head and is generally represented in the so-called turbine hill chart (Fig. 2), expressed in unit values, namely: unit speed $n_{l t}$ and unit flow q,

$n_{l}=\frac{n D}{\sqrt{H_{n}}}$
$q_{I}=\frac{q}{D^{2} \sqrt{ } H_{n}}$

From this figure, one can guess how efficiency drops if $\mathrm{n} /$ or $q$, deviate from their nominal values, which should be rather close to the hill peak. This can be brought about by changes in both the net head and the water flow. Besides the efficiency drop, some operational problems can arise in such situations. Part load fixed speed operation (FSO) with low heads can result in draft tube pressure oscillations and shaft torque fluctuations. In turn, fixed speed operation with higher than nominal heads can give rise to the appearance of cavitation . In order to avoid such problems, it is usual to set a narrow operating zone, usually defined by the minimum and maximum permissible net heads, and by the maximum power output of the generator . Beyond this operating zone, the above-mentioned problems are likely to arise.

the permissible net head of a Francis turbine has been found through experience to range from $65 \%$ to $125 \%$ of the design head. In addition, said reference recommends the turbine to always perform at efficiencies higher than $80 \%$.

Let's consider the case of a hydro generating unit, the turbine being similar to that of Fig. 2, associated to a reservoir, whose geometry is known. Net head depends on both the water discharge

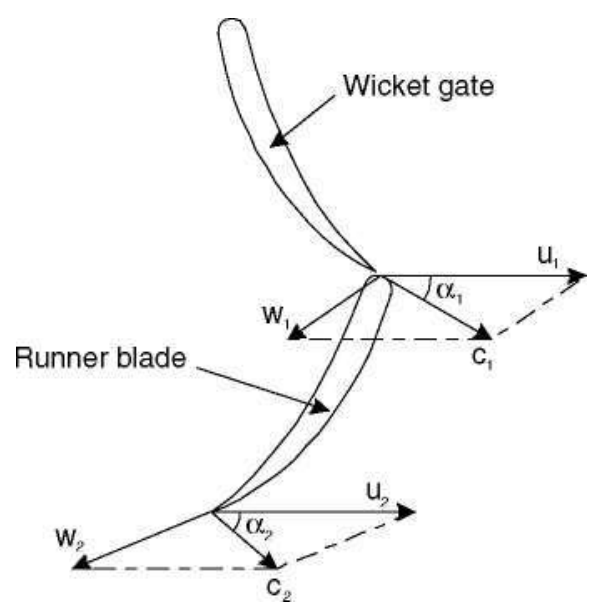

Fig. 1. Velocity triangles.

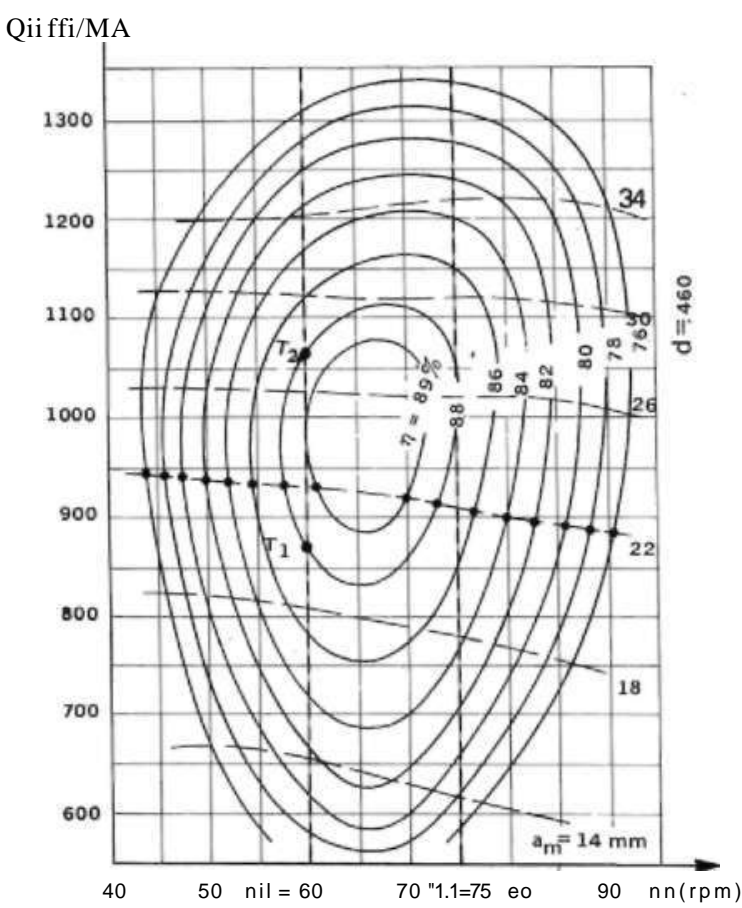

Fig. 2. Francis turbine hill chart [6].

through the turbine and the gross head, the latter being defined as the height difference between the reservoir level and the tailrace elevation. If we consider the head losses due to both water friction in the penstock and tailrace level variation as a quadratic function of the turbine water discharge, by means of an appropriate head losses coefficient, it is possible to obtain unit values of any operating point defined by: reservoir volume, water discharge and turbine speed.

Several performance curves, each of which corresponds to a given reservoir volume, have been depicted in Fig. 3 on a $n_{-}-\mathrm{q}$, plane, the turbine speed being assumed constant. Red lines in this figure delimit the turbine operating zone, defined according to the abovementioned criteria. From this figure, it can be seen that performance curves corresponding to lower reservoir levels are outside the feasible operating zone, thus reducing the amount of potentially harnessable energy. In addition, the above-mentioned drop in efficiency is easily noticeable in this figure, when compared with Fig. 2.

ASO main effects on a Francis turbine similar to that of Fig. 2 are embodied in Fig. 4. Firstly, it can be easily observed how, by adequately adjusting the turbine speed, performance curves can be displaced along the $\mathrm{n}_{-\mathrm{q}}$, plane, to the extent that, if turbine speed were also modified in accordance with water discharge, performance curves would superimpose the maximum efficiency line depicted in this figure. This not only allows to operate at higher efficiencies but also leads to a better use of the reservoir storage capacity since it is possible to operate the turbine over a wider range of reservoir levels. Secondly, for a given reservoir level, operating limits expressed in terms of water flow are enlarged. As it can be seen in Fig. 4, operating limits A and B turn into A and B', respectively, by increasing the turbine speed from its synchronous value $(250 \mathrm{rpm})$ up to $284 \mathrm{rpm}$.

Unregulated turbines with higher specific speeds, such as axial flow propeller turbines, are expected to be the most favoured by ASO , mainly due to the shape of their hill charts, since the maximum efficiency line is usually rather inclined 


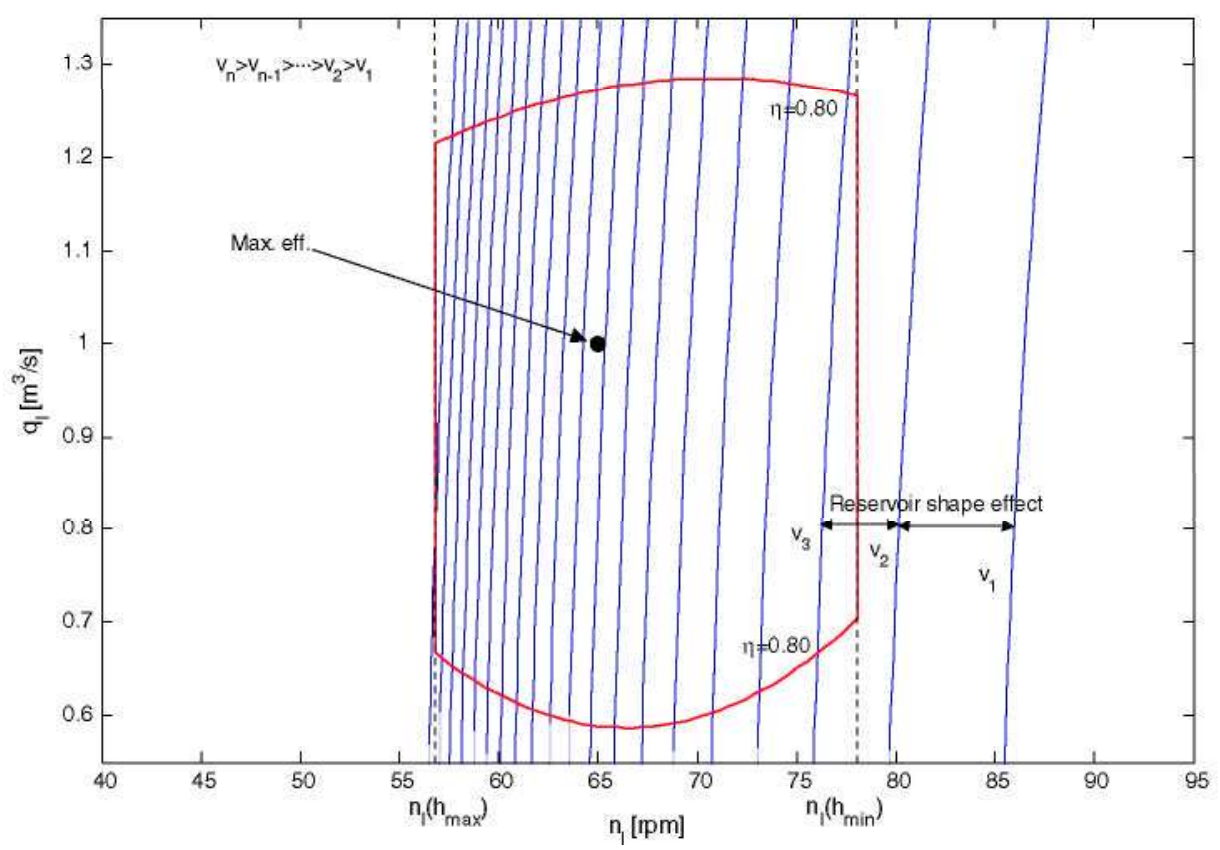

Fig. 3. Performance curves for different reservoir water levels.

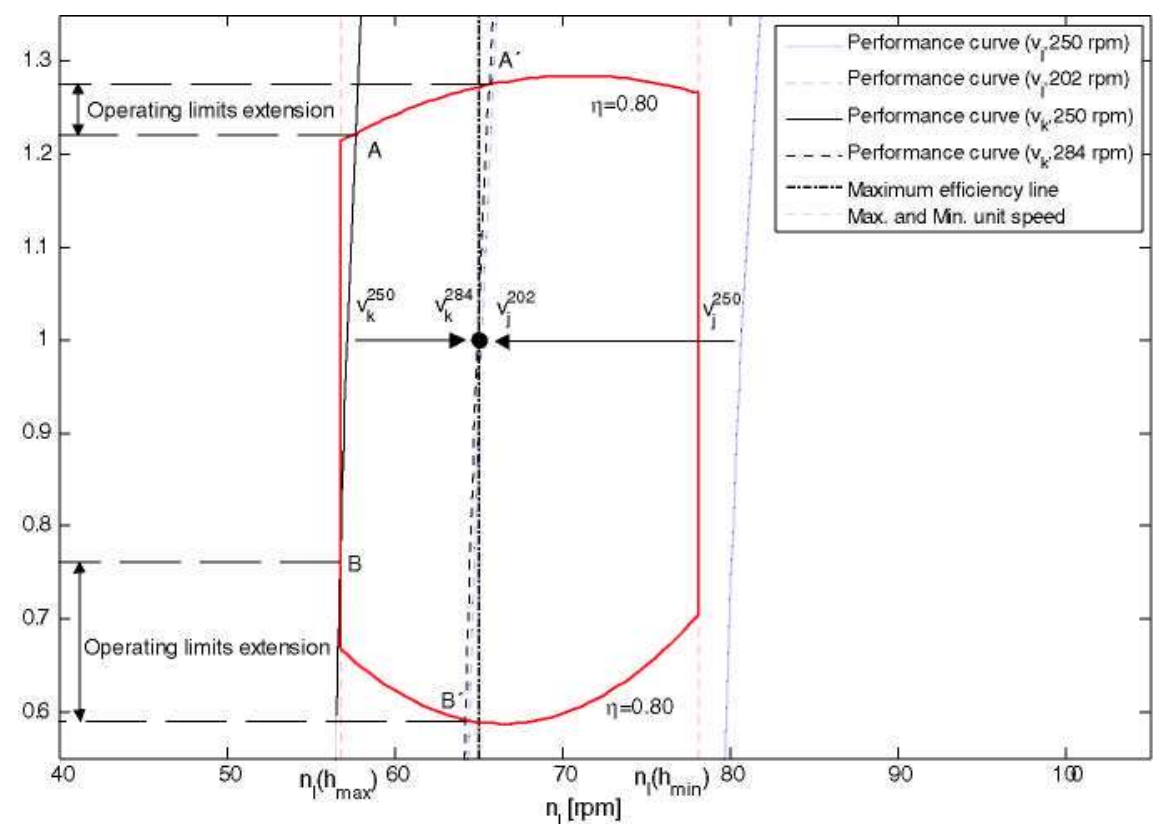

Fig. 4. ASO main effects on a Francis turbine generating unit.

\section{Simulations}

In order to illustrate the above-mentioned ASO features, some simulations have been carried out in a double-purpose reservoir located in the northern area of Spain, where irrigation use has priority over hydropower generation. Although this power plant actually consists of two identical Francis units, it will be assumed, for the sake of comparison, that it consists of an only Francis unit, similar to that used in section II to illustrate the main ASO effects.

Firstly, several performance curves (power generated in terms of reservoir water level and flow through the turbine) with both fixed and adjustable speed, were obtained by interpolating the efficiency from the turbine hill chart (see Fig. 5a-c). As it can be seen in Fig. 5a, FSO is not possible when the reservoir is below a certain level. In addition, ASO always provides better power values, except for those cases where the operating point is close to the peak of the hill chart. In these cases, the power provided by FSO is at most equal to that provided by ASO. Operating limits corresponding to different reservoir levels are compared in Table 1, where $q_{\min }$ and $\mathrm{q}_{\max }$ are respectively the minimum and maximum flow values, and $h_{g}$ represents the gross head. The enlargement of the range of operating flows proved to be somewhat disappointing, to a large extent due to the shape of the hill chart. Nevertheless, it seems reasonable to expect better results with unregulated turbines with higher specific speeds, such as axial flow propeller turbines. 

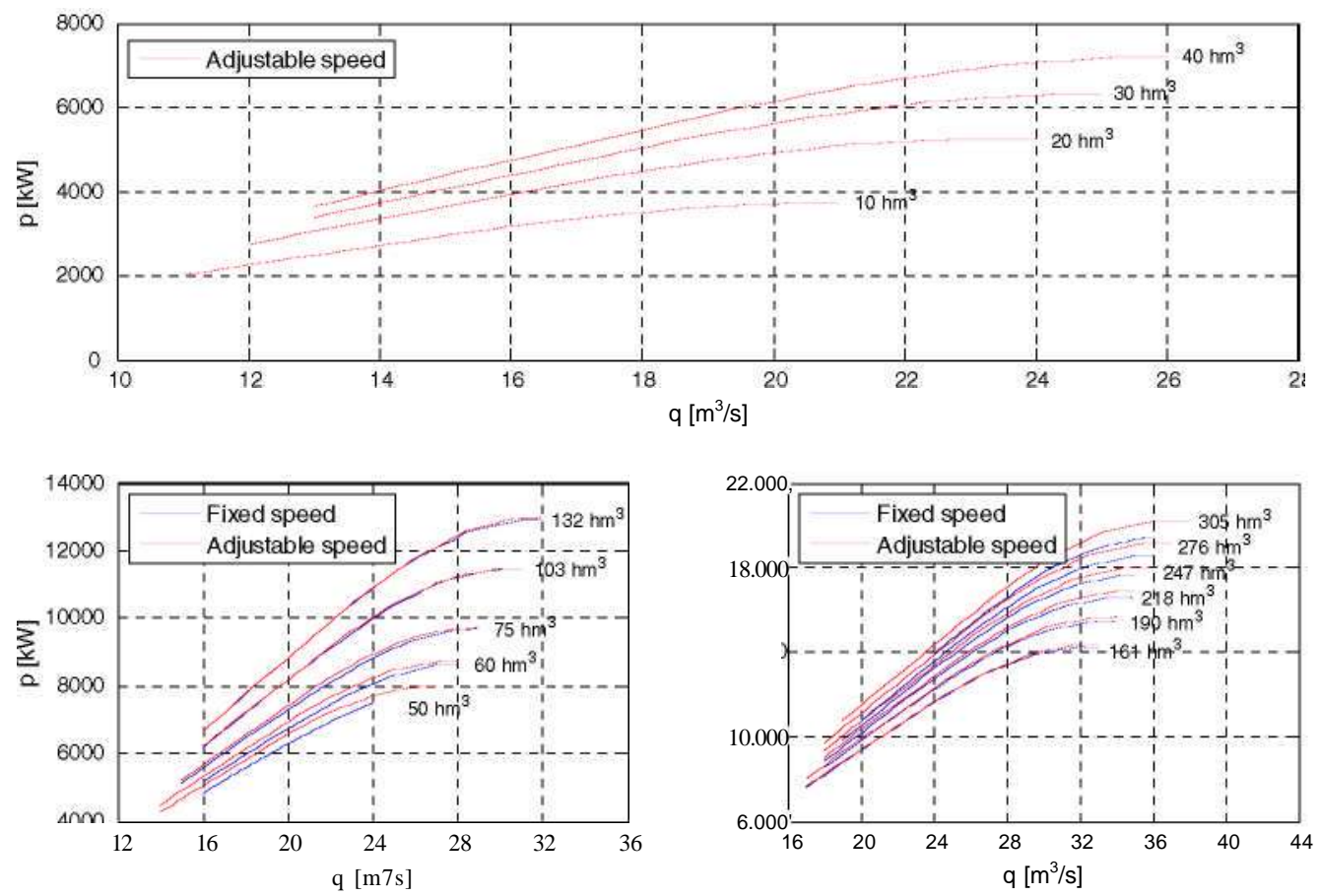

Fig. 5. Plant performance curves: (a) low reservoir levels; (b) medium reservoir levels; (c) high reservoir levels.

Table 1

Operating limits comparison

\begin{tabular}{lccclcc}
\hline $\mathrm{v}\left(\mathrm{hm}^{3}\right)$ & $\left.\mathrm{M}^{\mathrm{m}}\right)$ & \multicolumn{2}{c}{ Fixec speed } & & \multicolumn{2}{c}{ Adjustable speed } \\
\cline { 3 - 5 } & & Qmin $\left.\mathrm{m}^{3} / \mathrm{s}\right)$ & $9 \max \left(\mathrm{HI}^{3} />\right)$ & & $9 \mathrm{mi}_{\prime \prime}\left(\mathrm{m}^{3} / \mathrm{s}\right)$ & $\mathrm{q}_{\max }\left(\mathrm{m}^{3} / \mathrm{s}\right)$ \\
\hline 10.00 & 23.22 & 0 & 0 & 11 & 21 \\
20.00 & 29.20 & 0 & 0 & 12 & 24 \\
30.00 & 32.99 & 0 & 0 & 13 & 25 \\
40.00 & 36.00 & 0 & 0 & 13 & 26 \\
50.00 & 38.59 & 16 & 24 & 14 & 27 \\
60.00 & 40.88 & 16 & 28 & 14 & 28 \\
75.00 & 43.95 & 15 & 29 & 15 & 29 \\
103.75 & 49.03 & 16 & 31 & 16 & 31 \\
132.50 & 53.29 & 16 & 32 & 16 & 32 \\
161.25 & 57.01 & 17 & 33 & 17 & 33 \\
190.00 & 60.37 & 18 & 34 & 17 & 34 \\
218.75 & 63.44 & 18 & 35 & 18 & 35 \\
247.50 & 66.30 & 19 & 35 & 18 & 36 \\
276.25 & 68.98 & 20 & 36 & 18 & 37 \\
305.00 & 71.51 & 24 & 36 & 19 & 38 \\
\hline
\end{tabular}

Secondly, annual simulations have been done in 12 different scenarios, given by different weekly inflows and different initial reservoir volumes. Simulation scenarios were selected from an available historical series of average weekly inflows for a period of 26 hydrological years. The driest, the closest to the average, and the most humid years were selected for simulations (A, B and $\mathrm{C}$ in Table 2). With respect to the initial reservoir volume, four different values between the minimum and maximum values were selected for simulations (I, II, III, and IV in Table 3).

Table 2

Simulation scenarios: annual inflows $\left(\mathrm{hm}^{3}\right.$;

Scenarios

Hydr. year

Annual inflow $\left(\mathrm{hm}^{3} \wedge\right.$

Table 3

Simulation scenarios: initial volume $\left(\mathrm{hm}^{3 \wedge}\right.$

Scenarios

Initial volume $\left(\mathrm{hm}^{3}\right.$

221.51

$73-74$

$87-88$

407.26

637.17
As it was previously stated, this reservoir is used with priority for irrigation purposes. Thus, weekly irrigation flow guidelines are imposed by watershed authorities. In addition, several reservoir operating rules are to be satisfied, namely:

(a) When the reservoir volume falls below $50 \mathrm{hm}^{3}$, irrigation flow must be reduced to $80 \%$ of the guideline value.

(b) When the reservoir volume falls below $30 \mathrm{hm}^{3}$, irrigation flow must be reduced to $50 \%$ of the guideline value.

(c) When the reservoir volume rises above $281 \mathrm{hm}^{3}$, turbine

(d) When the reservoir volume rises above $292 \mathrm{hm}^{3}$, turbine must operate at full load $\left(\mathrm{q}_{\max }\right)$, and spillway gates must begin to open up, thus avoiding the reservoir level to keep going up.

(e) Watershed authorities have also fixed the so-called ecological flows, which are to be continuously spilled so as to satisfy environmental requirements: $0.72 \mathrm{~m}^{3} / \mathrm{s}$ from December to March; and $0.36 \mathrm{~m}^{3} / \mathrm{s}$ from April to November.

Simulation results are summarized in Table 4. As it can be observed from this table, in all cases analyzed, the energy generated by ASO proved to be higher than that generated by conventional FSO. The additional energy provided by ASO ranges from $0.67 \%$ up to $42 \%$ of that provided by FSO, the average being almost $20 \%$.

Results from one of the cases analyzed are shown in Figs. 6 and 7. Two different situations can be observed from these figures: must operate at full load $\left(\mathrm{q}_{\max }\right)$. 
Table 4

Simulation results

\begin{tabular}{|c|c|c|c|c|c|c|}
\hline \multirow[t]{2}{*}{ Scenarios } & \multirow{2}{*}{$\frac{\text { Fixed speed }}{\text { Energy }(\mathrm{MWh})}$} & \multirow[b]{2}{*}{ Weeks in operation } & \multicolumn{2}{|c|}{ Adjustable speed } & \multicolumn{2}{|c|}{ Additional energy } \\
\hline & & & Energy (MWh) & Weeks in operation & (MWh) & $(\%)$ \\
\hline I.A & 8056 & & 9973 & 9 & 1917 & 23.80 \\
\hline I.B & 15110 & & 21521 & 12 & 6410 & 42.42 \\
\hline I.C & 46362 & 18 & 53738 & 22 & 7376 & 15.91 \\
\hline II.A & 9659 & 8 & 11603 & 10 & 1944 & 20.12 \\
\hline II.B & 18178 & 9 & 24657 & 13 & 6480 & 35.65 \\
\hline II.C & 49531 & 19 & 57021 & 23 & 7489 & 15.12 \\
\hline III.A & 22559 & 16 & 22710 & 16 & 151 & 0.67 \\
\hline III.B & 30563 & 13 & 37301 & 17 & 6738 & 22.05 \\
\hline III.C & 62221 & 23 & 70108 & 27 & 7887 & 12.68 \\
\hline IV.A & 28347 & 15 & 34790 & 19 & 6444 & 22.73 \\
\hline IV.B & 48809 & 19 & 57324 & 24 & 8516 & 17.45 \\
\hline IV.C & 81133 & 29 & 86446 & 32 & 5313 & 6.55 \\
\hline
\end{tabular}

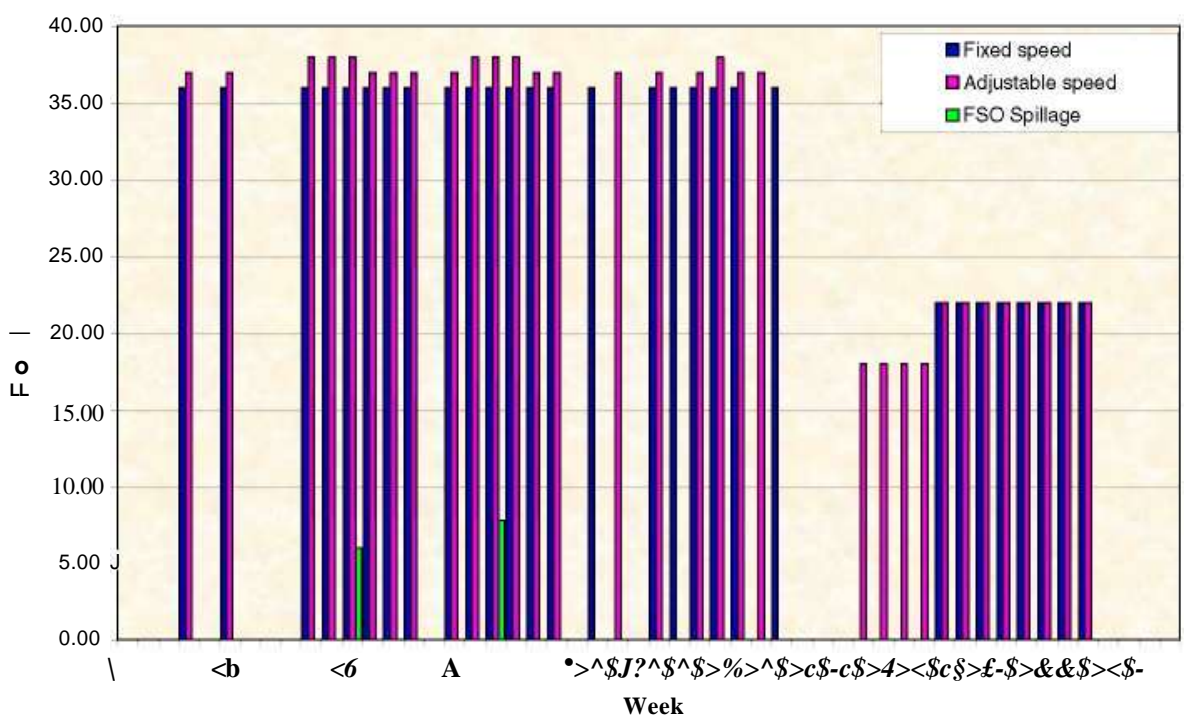

Fig. 6. Simulation results (scenario IV.C): water discharge.

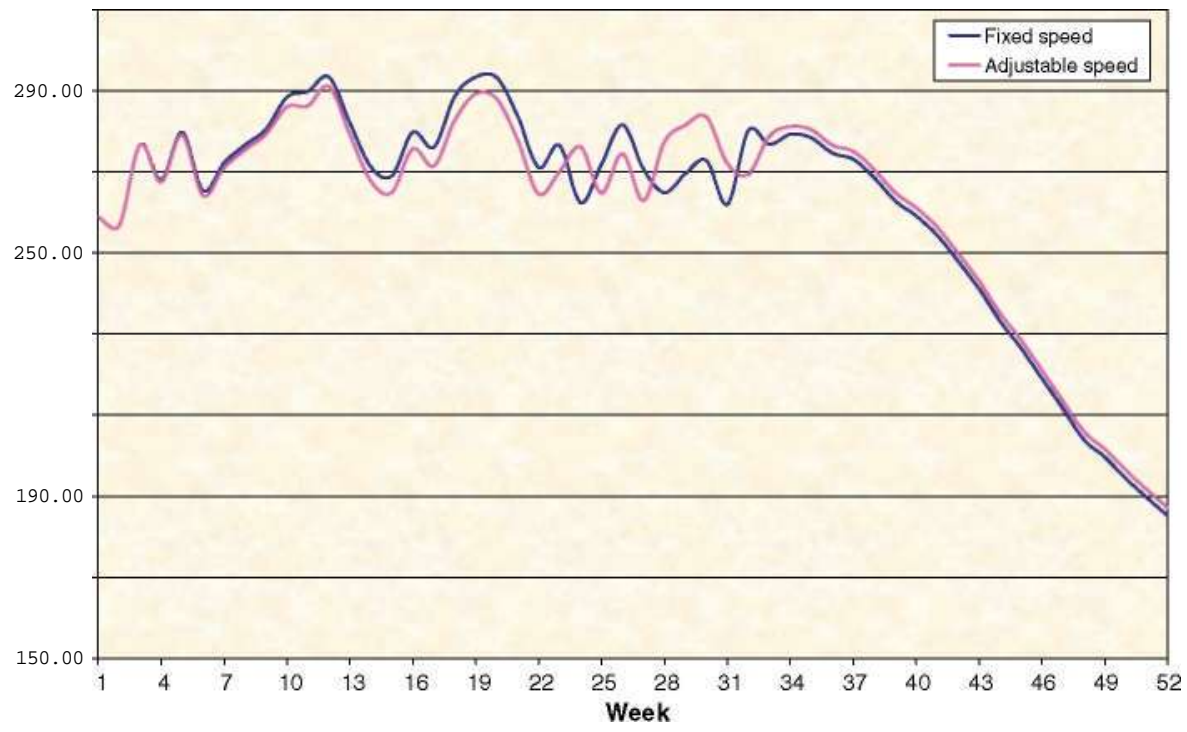

Fig. 7. Simulation results (scenario IV.C): reservoir volume. 
(i) During the first 33 weeks of the hydrological year, the plant operates at full load in order to satisfy operating rule c. The above-mentioned enlargement of the range of operating flows, although somewhat disappointing at first glance, allows that the turbine operates with higher flows during this period, thus avoiding water releases over the spillway.

(ii) From week 37 to week 40, the minimum flow necessary for FSO is $20 \mathrm{~m}^{3} / \mathrm{s}$, whereas the flow imposed to satisfy irrigation requirements is $18 \mathrm{~m}^{3} / \mathrm{s}$, so FSO is not feasible during this period. However, ASO is indeed possible during these weeks since the minimum flow for operation is $18 \mathrm{~m}^{3} / \mathrm{s}$.

Lastly, it should be noted that, in the case analyzed in this paper, results strongly depend on irrigation flow guidelines and on how inflows to the reservoir are distributed throughout the simulation period.

\section{Conclusions}

This paper deals with the issue of adjustable speed operation (ASO) of hydropower plants. Technical aspects of such technique have been further discussed, its main advantages being summarized as follows.

Firstly, in hydro plants with certain regulating capacity, that is, associated to a reservoir, ASO allows the plant to operate over a wider range of reservoir volumes. Secondly, ASO also enlarges the range of operating flows, especially in the case of high specific speed turbines such as axial flow propeller turbines, which may result in significant improvements in the case of run of river hydropower plants. In summary, it can be stated that ASO allows better use of the available energy resources and greater flexibility for energy dispatch.

Thirdly, ASO allows the turbine to operate at higher efficiencies, thus increasing the amount of energy generated and avoiding the appearance of operational problems such as cavitation, draft tube pressure oscillations and shaft torque fluctuations. As a consequence, equipments life can be extended and, in turn, long term maintenance requirements can be significantly reduced.

ASO of a hydropower plant associated to an irrigation reservoir has been simulated in order to confirm the above-mentioned advantages. The range of operating reservoir volumes is appreciably widened whereas that of operating flows is enlarged in much less proportion than the previous one, to a large extent due to the type of turbine used for simulations. Even though the enlargement of the range of operating flows is barely appreciable, it has considerable effects on the results. Regarding the energy gains, an average additional energy of almost $20 \%$ of the energy generated by conventional FSO, has been obtained.
The choice of an irrigation reservoir was motivated by the idea that, when implemented as part of a multipurpose water resources development scheme (drinking water, irrigation, etc.) with an existing reservoir, a hydro station can offer a number of side-benefits, , since

the majority of the environmental impacts have already occurred at these sites. Anyway, it should be pointed out that economic aspects, such as the additional investment in electronic devices necessary to perform ASO and the expected pay back period, are to be studied in each particular case.

Lastly, two lines of work are proposed to further study the possibilities and limitations of ASO. It would be of great interest to undertake the present study with an unregulated axial flow propeller turbine, and to compare the saving in turbine cost along with the energy gains against the additional investment in electronic devices necessary to perform ASO. Nowadays, many low-head sites with moderate flows, where head and flow deviations are significant in relative terms, are rejected due to their lack of cost-effectiveness. In this sense, ASO of axial flow propeller turbines may contribute to the development of several mini and micro hydro schemes, which have so far not been exploited.

It would be also interesting to study the possibility of installing adjustable speed generating units to produce energy from ecological flows in power stations located at the toe of a dam. Said flows are to be continuously released in order to maintain the natural habitat for the river basin fauna and flora, whatever the reservoir water level, so ASO may offer an attractive solution to cope with such head variations.

\section{References}

DG-RTD's Advisory Group on Energy. Further tasks for future European Energy R\&D. Belgium: European Communities; 2006.

Bartle A. Hydropower potential and development activities. Energy Policy 2002;30:1231-9.

DG for Energy and Transport. Status report on variable speed operation in small hydropower. Austria: European Communities; 2000

Bard J et al., Vasocompact - a European Project for the development of a commercial concept for variable speed operation of submersible compact turbines. Unpublished.

Campos JG, Saidel MA, Ingram L, Westphalen M. Adjustable speed operation of hydroelectric turbine generators. Electra 1996;167:17-36.

Mataix C. Turbomaquinas hidraulicas. Madrid: ICAI; 1975.

Finardi EC, da Silva EL Unit commitment of single hydroelectric plant. Electr Power Syst Res 2005;75:116-23.

US Department of the Interior: Bureau of reclamation. Selecting hydraulic reaction turbines. A water resources technical publication, Engineering monograph No. 20; 1976.

Farrell C, Gulliver J. Hydromechanics of variable speed turbines. ASCE J Energy Eng1987;113(1):1-13. 